\title{
Indigenous African Music: A Descriptive Analysis of Mmino wa Setšo from a Northern Sotho Perspective
}

\author{
Madimabe Geoff Mapaya \\ University of Venda \\ Email: geoff.mapaya@univne.ac.za
}

Doi:10.5901/mjss.2014.v5n20p2211

\begin{abstract}
Mmino wa setšo has been interpreted from different angles. Most notably, these schools of thought are interpretative, but with a considerable amount of misrepresentation. As such the efforts of bringing this and similar genres to the centre of scholarship are undermined. Drawing from interviews, observations and discussions with practitioners of the genre, this article attempts to proffer a descriptive analysis of mmino wa setšo. Whereas the presentation is in scholarly prose, the wish is to remain honest to the initial intentions and ideations of the practitioners. Cognisant of the discrepencies that still need to be addressed, this paper is an attempt at a type of African musicology, which seeks to capture the essence of the abstractions of the practitioners.
\end{abstract}

Keywords: mmino wa setšo, indigenous African music, molodi, African rhythms, African drumming.

\section{Introduction}

Early scholars including Dewey (1934) and Merriam (1964) have shown in their writings that music is, at an intellectual and emotional level, a construct of culture, and as such, a product of society. Taking this theory a step further, particular music is a construct of a particular society. Punk music would, for instance, be associated with the punk lifestyle and thus is the product of such a society; and likewise gospel music is the music of Christiantity. But the dangers of pursuing adjectives when designating or dealing with universal phenomena such as music are forever present in any discourse, especially if we subscribe to the notion that says music is music (Babbitt, 1958). Cognisant of such dangers, we, nonetheless, note that Northern Sotho people distinguish between mmino wa sebjalebjale (modern music) and mmino wa setšo-a Northern Sotho designation generally used in reference to indigenous (African) music. This kind of dichotomisation enables them to insulate mmino wa setšo from undesirable influences; hence even up to today mmino wa setšo is devoid of the domineering I - IV- V harmonic formula, which both Akrofi (2003) and Agawu (2008) rightfully acuse of being a colonising force. Practitioners of mmino wa setšo would rather acculturate other encroaching music styles by infusing or rather injecting indigenous principles into, than have such music alter mmino wa setšo, per se. A typical example of this one way process can be seen in the resultant Africanisation of the music of the African Independent Churches, and also the infusion of African musical ethos into jazz resulting in the so-called African jazz (Makgopa et al., 2012). Mmino wa setšo has remained purely a socio-cultural construct of the Northern Sotho performative compound which entails song ${ }^{1}$ on the one hand and dance on the other. Although other art forms also feature in this performative tradition, it is the dominance of song and dance which seems to have captured the essence of the practice.

In this article the concept of song is restricted to singing, and likewise dance to dancing only. Mmino wa setšo comes in three forms, which are general instrument playing, singing, and dancing. The following is but an exposition of these forms. Mindful of the many attendant abstractions, the study yielding this paper purposefully relied on the Northern Sotho ideations distilled from fieldwork and lived experiences; that is, how the Northern Sotho people themselves, through their vernacular language and terminologies, explicate ideas about the practice, and how they go about meaningful discourse of musicology.

\footnotetext{
1 Unlike the concept 'music', which hardly has an African equivalent, the concept of 'song' is preferred in its place because of its close association with the Northern Sotho concept of koša.
} 


\section{Understanding Drumming in Mmino wa Setšo}

In ensemble performance genres such as dinaka (a historically male only instrumental musical genre) and mokangkanyane (essentially a female song-dance genre) drumming forms a common denominator, thus a distinctive feature of mmino wa setšo performative tradition. Almost all musical performances involve drumming, and some dancing. This perhaps explains the attention and the focus by the many a scholarly texts on African drumming, and by extension African rhythm, almost to the exclusion of other elements. Whereas singing and instrument playing receive some attention here and there, drumming, and to some extent dancing, are by far the most discernible features of indigenous African music.

Studies of drumming from the West Africa experience are plentiful; yet, little about drumming in the south of the continent is known. Northern Sotho and Vhavenda people are some of the ethnic groups in South Africa whose music, especially ensembles, features extensive drumming. Even though John Blacking has written extensively about muzika wa Vhavenda (Venda music), the drumming aspect of the music seems to have eluded his scrutiny. The presence of drumming within the music ensembles in these communities presupposes the presence of a strong cultural affinity with the drum.

Needless to say, drumming is seldom discrete, and as such it is shared by the community. Also drumming, if added to certain ritual dancing, propels participants from an ordinary state of consciousness into orbits of spirituality. It moves people. According to Sebaiwa (2005), without drumming, music would not be able to 'move' people to dance; this is an African perspective, of course. Sebaiwa uses the word 'move' metaphorically. Yet in the literal sense, drumming involves coordinated body movements, which often compels the producer of sound (as music) to move physically and the perceiver to dance. Furthermore, drumming marshals allied arts formations into some synchronised occurrences. The drum amplifies motion (often gestured movement or dance) in relation to performed music, thereby giving ordinary body movements a dramatic character. After all drumming, in itself, is music-making even though music-making is not necessarily drumming.

Universally, rhythm is a strong element associated with percussion instruments. Depending on the conception of melody, meropa (drums) may be tunes in such a way that they express melodic ideas. An example would be the idea of the talking drum. The close association of the melodic and rhythmic drum capabilities of drumming finds expression in Nzewi's (1974) preference of the concept, 'melorhythm'. The melorhythmic capabilities of African drumming are further evidenced by its ability to communicate messages. This speaks to what Arom $(1991 ; 2009)$ refers to as the drum language. Alert to this strong feature of melorhythm, African scholars-and indeed practitioners of indigenous music-have adopted this system for use in other musical scenarios. Kwami (1998) and Nzewi (2007) refer to mnemonic and onomatopoeia systems of transmitting musical ideas between sets of communicators.

Amongst communities, similar systems wherein vowels are utilised to represent different hand strokes during drumming exist. For example, dithopana - small drums used in dinaka, mokankanyane, and to a lesser extent dipela, are said to be 'singing' the phrase, ditapola ka pitšeng, ditapola ka pitšeng ditapola ka pitšeng ditapola ka pitšeng or alternatively tu du ghu tu du ghu tu du ghu.

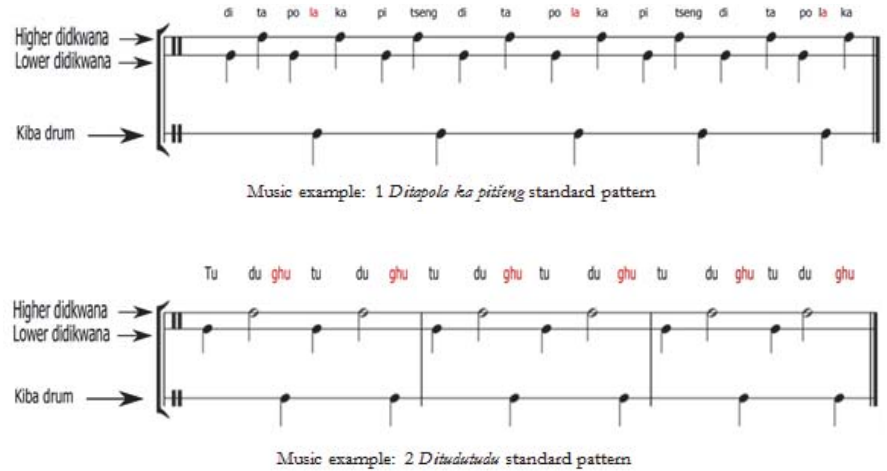

In both musical examples, the top two lines represent a unit of dithopana drums which may be allowed limited scope for variations while the regular line is executed on kiba (the big drum). At a higher level, a combination of dithopana and kiba forms one compound unit responsible for the pulsation and propulsion of a performance. 


\section{Understanding Dancing within Mmino wa Setšo}

Dancing is an integral part of mmino wa setšo performance, and several genres feature this musical condition (Mapaya, 2014). A critical analysis of male dance routines, for instance, reveals a kind of a warrior tradition, which often celebrates masculinity and virility. The affinity with the Scottish kilts by some dinaka groups, the preference of police or military-like outfits by performers within the nkedi (a kind of musical practice within the Zion Christian Church) performance genre (Mapaya, 2013), or the adornment of wild animal skins and the brandishing of 'traditional weapons' by most dinaka dancers are commonplace features, translating into the celebration of historic warrior and hunter male performer experience.

On the other hand, female dances within their subtle stratifications, generally exhibit a celebration of femininity and national or communal fertility. During such dance routines, the aesthetics of the female body movement and shape are exhibited through the seemingly effortless waist wiggling. Yet, fertility is not restricted to the biological factors but also includes that of the land in any given season. Go thekela (a female graceful dancelike-walk-across a male dominated dinaka performance), much as it is a dance and a mark of general performance appreciation by a 'moved' female spectator, is also an exhibition of the beauty of the very woman engaged in the act.

But to draw a rigid line between the aforementioned gender-based categories of dance behavioural patterns would be misleading since a significant crosspollination of some tendencies abound. It is common, for instance, to find mature graceful women brandishing soft war paraphernalia such as wooden axes or spears during performances. Similarly, in the mist of the masculine dance routines, there would be moves around a male dancer's waist area suggesting sexual nuances. The late Simon Nkabinde, popularly known as Mahlathini of the Mahlathini and the Mahotlla Queens group (Ballantine, 1989), had a repertoire of such moves. It is also common for male dancers to wear female undergarments such as petticoats as a deliberate attempt to amuse the spectators. Perhaps the most prevalent evidence of this blurring of the lines would be around the soukous dance routines, which originate from the Central Democratic Republic of Congo (Frank, 2003).

\section{Dancing - Drumming Interlocution}

Bailey (1985) asserts that music is the sonic product of action. Conversely though, it is not farfetched to infer that, action, or dance to be more precise, is a responsive behaviour to music: much like the chicken and egg scenario. In mmino wa setšo, and certainly in other forms of indigenous African music, a strong relationship between movement (be it gestured movement or dance) and the sonic product, exists. Amongst baletši (purportedly instrumentalists or Northern Sotho cultural practitioners of mmino wa setšo), for instance, reference to most musical renditions fluctuates between what is referred to as moletse (dance pattern or dance routines) and koša ${ }^{2}$ (song sung vocally in text or hummed, as well as an instrumental tune). This two-dimensional description; featuring song on the one hand and dance on the other manifest into a situation where phrases such as go bina koša are loaded in meaning. Perhaps what had not been highlighted enough in previous scholarly works is that song and dance, as they occur in mmino wa setšo, feature instrumental interlocution of some kind, particularly drumming.

Thus, most genres of mmino wa setšo invite dance (Mapaya, 2010). For instance, in dinaka, malopo, dipela and mokankanyane and the majority of social gathering performances, a strong relationship between drumming and dancing exists. And it is not always obvious as to which, between the drum rhythms and meletse (body movements or a dance) direct the musical happenstances. In other cases, meletse seem to suggest certain types of songs, while in others koša suggests certain meletse. It is clear though that meletse, moribo (the musical groove) and merethetho (drum rhythms) have between them a complementary element, which together makes up what scholars such as Mead (1999) and Kofie (1994) refer to as 'musical understanding'. It is therefore reasonable to assert that some songs are 'composed' in accordance with desired dance types or movements. And certain movements, either in the context of a game or as meletse, form the basis for some Northern Sotho song structures. This phenomenon is not unique to the music of Northern Sotho people, but occurs in other dance styles such as the Latin American Cha-cha-cha or waltz and foxtrot in central European music. As Nketia (1992:177) puts it, "form may be influenced ... by the nature of the movements and expression with which such music is integrated". In other words, the arrangement of musical ideas within a musical performance may as well be designed or planned around body movements, dance movements or even ensemble movements. By recognising the dynamic relationship between movement and song, we ready ourselves for the next level of understanding.

\footnotetext{
2 The term koša is reducibly used to denote song whereas in fact, it means performance, which naturally implicates primarily song, dance, and expressions of other art forms.
} 


\section{Singing within Mmino wa Setšo}

The impact of text-singing is immediate because words immediately transmit meaning; and meanings evoke an array of responses. The kind of responses can assume an entirely new impetus if the words are performed: be that in recitation, song or other oratorical vehicles. At these specialized performative levels, the voice becomes an instrument that delivers messages in the form of texts.

Northern Sotho people, like all peoples, use the voice in several ways to a great effect to achieve an array of objectives. Often the goal is to coat the message in appropriate prose in order to achieve predetermined objectives. Scolding, a vocal performance in its own right, is meant to cause harm or emphasise the seriousness of cause and effect in human relations; praise poetry invokes a sense of pride and serenading, feelings of love and affection. Besides, the voice is one of the most versatile musical instruments (Nakkach \& Carpenter, 2012) capable of intricate musical gymnastics. In most instances the voice is used together with other musical instruments; and in such contexts it is often considered the most important feature.

Singing can be viewed in two categories; text-singing and non-text-singing. Text-singing is perhaps the most discernible province of melody in mmino wa setšo. Mokankanyane, for instance, strongly feature a broad range of text messages crafted in stylistic melodic frames. Extemporisation, poetry recitation, and indeed scolding are some of the modes through which text messegess are set in motion. Once in motion, these texts assume, to an extent, some level of liberation from the constraints of ordinary spoken language (Agawu, 1988); often enjoying poetic impunity which is embedded in poetic licence (Perloff, 1990).

Non-text-singing may be viewed from three manifestations. Vocalic lilting - an Africa-specific technique - is utilised mainly for texture of harmony building. Setu is also a section within song performance where the melody is implied through humming. Still on non-text-singing, a phonologically similar term to melody molodi (melodi = plural form) which connotes whistling exists in Northern Sotho culture. Apart from its capability to carry the melody, molodi is also capable of long-throw, medium-throw, short-throw calling, and other properties amenable to soothing and/or commanding.

Go letša molodi (whistling) comes in no less than three distinct forms, with a few closely relating to music-making: 1) One may whistle in an attempt to attract the attention of (in other words to call) someone who is a distance away; 2) it can also be used in an exclamatory manner to mark astonishment; and 3) whistling can be musical when it carries the (molodi wa koša) melody of a song. The ability of molodi to execute contours similar to those of short to medium melodic phrases, and its piercing long distant throw makes it amenable to signature calling, as in tsotsi whistling. Could the effect of molodi on a cow that is being milked, on calling a straying bull or cow back into the herd, and on halting a span of cartpulling donkeys hold a key to understanding whistled gestures? Are these known effects of 'molodi' suggesting that it is tantamount to melody of the Western conception? Is molodi wa koša (the whistle of a song/performance) perhaps a workable invention?

The lingering melody, which is none of the above, but still a kind of non-text 'singing', is equally crucial in establishing ensemble cohesion. An example for lingering melody was evidenced by one dinaka group in Thembisa. In rendering Seberuberu, one of their favourite koša, they broke into vocal singing. But the text-signing melody seemed to have little connection with the prevailing hocket style polyphony. How is it that everybody seems to know what song it is and how it should be performed? This suggests that the melody has all along been present in the minds of performers amidst the polyphony of go dumela, a kind of textured musical response and the accompanying moletse. The same technique is used by jazz improvisers who, apart from following the harmonic structure of the piece, may choose to rely on the lingering melody or tune of the piece. By so doing, the soloist and the accompaniment maintain a common sense of place in the musical progression.

\section{Instrument Playing}

Northern Sotho people play a range of instruments: Along with drumming, they play dinaka (reed or pen pipes), dipela (thumb pianos), and makope (wooden flutes). Meropa and dinaka are associated with ensembles while dipela and makope are more of intimate solo instruments. In other words, meropa and dinaka are more communal as opposed to dipela and makope; even though dipela tša harepa (acculturated harp forms of dipela) can be solo or feature as the main instrument in small ensembles.

In instrument playing an array of melodic formulae exists, and it is largely dictated to by the genre involved. Melodic instruments such as makope are single line instrument. In this sense it is easy to discern the melody. But as far as dinaka are concerned, it is hard to identify the melody because of the hocket nature of performance. One naka 
produces one fixed note. Therefore it requires a number of dinaka to produce a single sensible melodic phrase. In dinaka genre the phrases that the performers produce do not conform to the notion of melody but a weaving of musical texture. When singing finally occurs in such performances, the melody seems different from the instrumental texture formed as a result of simultaneous melodies a la hocket style otherwise referred to as oral polyphony (Arom S., 1976).

The overemphasised call-and-response melodic formula perhaps more prevalent in vocal music, may not enjoy the same status in instrumental ensemble such as dinaka, or it may not exist at all in solo instrument playing. Conglomerate melodies - those that arise out of the hocket interweaving - are possible in dinaka whereas surrogate melodies forming part of go dumela seem to have their own logic since they, in their independent origination, complement other melodies.

But dipela, which is more of a solo instrument genre, draws its character from the two principles of instrumental and vocal singing obtaining within dinaka and mokankanyane practices: in dinaka, text is sung while the instruments provide go dumela. In dipela, we have three ways of indexing a piece of music; this could be done from the sung text (melody), accompaniment in the form of go dumela (harmony) and moletse-cum-drum pattern (choreography). This character evidences the fact that in Northern Sotho, melody exists, but not always as explicit as it is the norm in Western music. It can be somewhat silent and implicit within the act of go dumela; and moletse wa koša can be sufficient as a defining feature of a song performance.

\section{Conclusion}

This paper presented a brief but concise description of mmino wa setšo. It has done so by highlighting salient features such as drumming, singing, communication between drumming and dance, and instrument playing. Whereas this information is not exhaustive, it could serve as the basis for further research. Scholars of African music are challenged to test some of the assertion and do comparable analysis with what obtains in other regions. Only when all the areas of interest are covered can we begin to fashom a type of musicology which is relevant to the growth of knowledge within the phenomenon of African music.

\section{References}

Agawu, K. (2008). Tonality as a Colonizing Force. Tonality in Perspective. King's College, London: Royal Musical Association Paper. Agawu, V. (1988). Tone and tune: The Evidence for Northern Ewe Music. Africa, 127-146.

Akrofi, E. (2003). Tonal Harmony as a Colonizing Force on the Music of South Africa. [Online] Availavle: http://www.deakin.edu.au/artsed/education/music-ed/african-music/Akrofi_(2003).pdf/ (May 5, 2014)

Arom, S. (1976). The Use of Play-Back Techniques in the Study of Oral Polyphonies. Ethnomusicology, 20(3), 483-519.

Arom, S. (1991). African Polyphony and Polyrhythmic, Musical Structure and Methodology. Cambridge: Cambridge University Press.

Arom, S. (2009, April 24). Language and Music in Fusion: The Drum Language of the Banda linda (Central African Republic). [Online] Avilable: http://www.sibetrans.com/trans/index.htm (June 07, 2011)

Babbitt, M. (1958). "Who cares if you listen?". High Fidelity, 8(2), 38-40.

Bailey, J. (1985). Music Structure and Human Movement. In P. G. Howeel, Musical Structure and Cognition. London: Academic Press INC.

Ballantine, C. (1989). A brief history of South African Popular Music. Popular Music, 8(3), 305-310.

Dewey, J. (1934). Art as experience. New York: Minton Balch.

Frank., E. (2003). Loosening Up the Soul: Festival, Dance, and Ritual in Central Africa. In A. N. Leslie (Ed.), IROHIN: Taking Africa to the classroom (Vol. 36, pp. 31-34). Gainesville, FL: University of Florida.

Kwami, R. (1998). Towards a Comprehensive Catalogue of Eve Drum Mnemonics. Journal of African Cultural Studies, 11(1), $27-38$.

Makgopa, M., Mapaya, M., \& Thobejane, T. (2012). Infusion of Folklore into the South African jazz: An Analysis. Southern African Journal for Folklore Studies, 22(2), 119-127.

Mapaya, M. G. (2013d). Investigating Mmino wa Setšo (Indigenous African Music) as Practiced by Bahananwa in Limpopo Province, South Africa: Towards Ordinary African Musicology. PhD Thesis, University of Venda, Thohoyandou.

Mapaya, M. G. (2014). Rhythm or Rhythmic Incentive? An African justification of a common responsive musical behaviour. A paper presented at the International Journal of Arts and Sciences Conference. Las Vegas: International Journal of Arts and Sciences.

Mapaya, M. G., Malinga, J. M., \& Thobejane, T. D. (2014). The Anatomy of the South African Jazz Appreciation Societies. Journal of Social Sciences, 39(1), 59-65.

Mead, A. (1999). "Bodily hearing: physiological metaphors and musical understanding. Journal of Music Theory, 1-19.

Merriam, A. (1964). The Anthropology of Music. Evanston: North Western University Press.

Nakkach, S., \& Carpenter, V. (2012). Free your voice: Awaken to life through singing. Boulder: Sounds true, inc.

Nzewi, M. (1974). Melo-Rhythmic Essence and Hot Rhythm in Nigerian Folk Music. The Black Perspective in Music, 2(1), 23-28.

Nzewi, M. (2007). A Contemporary Study of Musical Arts Informed by African Indigenous Knowledge Systems: Illuminations, Reflections and Explorations (Vol. 4). Pretoria: Ciimda.

Perloff, M. (1990). Poetic license: essays on modernist and postmodernist lyric. Evanston, Illinois: Northwestern University Press.

Sebaiwa, P. (2005, 03 05). face-to-face interveiw. (M. Mapaya, Interviewer) University of Venda, Limpopo, South Africa. 